\title{
Importance of Measurement Parameters for the Dental Implant Surface Characterization
}

\author{
A. GUnAY ${ }^{a, *}$ B. SAgBAS ${ }^{a}$ AND M.N. DURAKBASA ${ }^{b}$ \\ ${ }^{a}$ Department of Mechanical Engineering, Yildiz Technical University, 34349 Besiktas, İstanbul, Turkey \\ ${ }^{b}$ Department of Interchangeable Manufacturing and Industrial Metrology, Institute for Production Engineering \\ and Laser Technology, Vienna University of Technology, Karlspl. 13/3113, A-1040 Wien, Austria
}

Pure titanium and its alloys have been widely used in biomedical applications on account of their biological and mechanical properties. Although the mechanical properties of titanium provide acceptable responses under dynamic pressures, surface modifications are needed in order to improve osseointegration between bone-implant interfaces. There are many different surface modification techniques like sand blasting, acid etching, or coating with various materials. Surface characterization is as important as surface modification for dental implants. Although many researchers studied about measurement of surface characteristics of dental implants with similar techniques but with different measurement parameters, there is still no consensus about the optimal surface characteristics values of a successful dental implant. Among many other surface characteristics, surface roughness is one of the most important features for dental implants. In this study, the importance of surface roughness measurement of dental implants is discussed and the need of a standardized procedure for implant surface roughness measurement is emphasized. In our experimental study three different processed surfaces as sand blasted and hydrofluoric acid etched surfaces, sand blasted and nitric acid etched surfaces and blasted surfaces were investigated. Results are compared via each method and each processing technique. It is aimed to highlight the importance of a standardized method for measuring and describing surface characteristics. More definitive, standardized methods are needed to augment the rather existing varied combined measurement parameters which affect the results for the assessment of biomedical surfaces.

DOI: $10.12693 /$ APhysPolA.125.484

PACS: $81.70 .-\mathrm{q}$

\section{Introduction}

Dental implants are currently used for restoration of lost teeth and to help form a new bone. Although they can be in different sizes and shapes, they can be manufactured from different biomaterials with different surface properties. These surface properties have been designed to provide textures and shapes that may enhance cellular activity and direct bone osseointegration $[1,2]$.

There are lots of important characteristics which define dental implant quality, desired from a successful implantation procedure. Besides providing macroscopic structure like material and shape, an implant should accomplish microscopic structure such as the chemical, physical, mechanical, and topographic characteristics of the surface. These different characteristics affect the activity of the attached cells that are close to the implant surface. Therefore cell proliferation, osteoblasts transformation, bone tissue formation and rate of osseointegration is affected by different surface topographies [2-4].

Implant-bone interface area is an object of great interest of researchers because of its critical role on osseointegration. Formation of a direct contact between implant and surrounding bone is crucial for clinical success [5]. It is widely accepted that surface properties of an implant such as composition, surface energy, topography

*corresponding author; e-mail: asligunaya@gmail.com and roughness influence the interaction of bone-implant interface. Bone formation is regulated by these surface properties [6].

Many research groups reported that surface roughness of a dental implant can accelerate osseointegration and bone healing process by increasing bone-to-implant contact. It provides better mechanical stability between bone tissue and the implant surface $[3,4,7]$. From this point of view, a crucial amount of researches focused on the surface topography characterization for different surfaces and methods that aim to define the adequate specifications for the osseointegration of dental implants. Surface characteristics can be classified as surface roughness, waviness and form. Surface waviness and form can be called as three-dimensional specifications. The roughness can be defined as two- or three-dimensional specification. ISO standards specify the rules, parameters for indication of these $2 \mathrm{D}$ and $3 \mathrm{D}$ surface texture by means of graphical symbols and textual indications $[8,9]$. These rules include different profiles $(\mathrm{R}, \mathrm{W}$, and $\mathrm{P})$, sampling lengths, filters and cut-off values. While defining the surface characteristics of a dental implant these parameters are used with a big variety of combinations. The measurement results may be changed according to these measurement parameters [10]. The results also may change in the relation with these parameter selections.

Based on the above addressed phenomena, in this study the importance of surface roughness measurement of dental implants is discussed and the need of a standardized procedure for dental implant surface roughness 
measurement is emphasized. Also the surface topography of three different sample groups was investigated by Form Talysurf Intra.

\section{Materials and method}

In this experimental research grade four titanium sample flat discs were used to characterize the surface specification by using various measurement parameter combinations. The discs were shaped $2 \mathrm{~mm}$ in radius with $0.6 \mathrm{~mm}$ thickness. Prior to the samples analysis, the titanium surfaces were modified by chemical etching and blasting techniques. The samples analyzed in this work were classified in three different groups.

The first group specimens were sand blasted. Their surfaces were blasted with titanium oxide $\left(\mathrm{TiO}_{2}\right)$ particles approximately $150 \mu \mathrm{m}$ in diameter with a blast pressure of $4 \mathrm{~Pa}$ for $40 \mathrm{~s}$. This procedure was applied by jets from a $20 \mathrm{~mm}$ distance and the $\mathrm{TiO}_{2}$ particles hit the surface with nearly $90^{\circ}$. A radial forceps held the test specimens during the blasting procedure to enable homogeneous blasting procedure. After this procedure the specimens were stored in isolated containers before other surface modifications.

The other two groups were both acid etched after sand blasting procedure. Acid etching of surfaces decreased the surface roughness. This decrease can be thought as a negative effect to the surface because, as it was emphasized before, rough surfaces showed better fixation owing to the strong interactions and the interfacial shear strength correlated positively with the degree of surface roughness.

In literature there is a big variety of studies that proves the importance of roughened topography advantages for a good osseintegration period [11-13]. But there are also other characteristics which have effective roles in osseintegration time interval.

In the literature there are reports which prove that initial interaction of surfaces is crucial for long time osseintegration interval. Acid etching technique is one of these processes found to be effective at wetting behavior of surfaces at initial interaction for specific hydrophilicity in contact with a liquid phase $[14,15]$. Different acid etching methods were also applied to investigate their effects to the surface. Second group was the blasted and etched group, had their surfaces waiting in a hydrofluoric acid (HF) bath. These specimens had two step modification procedures so called hybrid surface treatment. Specimen firstly had sand blasting procedure with same parameter of the first group and then the acid was applied to the surface. After sand blasting, the implants waited in a hydrofluoric acid bath for $12 \mathrm{~s}$. The last group had a similar procedure like second group; surfaces treated by a two-step procedure, firstly sand blasted same as second group and then had their surface treated by a hydrochloric acid $(\mathrm{HCl})$ bath, followed by a hydrofluoric acid ( $\mathrm{HF})$ and nitric acid $\left(\mathrm{HNO}_{3}\right)$ baths.

It has to be noted that, prior to the analysis, all the samples were cleaned in an ultrasonic bath. All surface treatments of materials (polishing, sandblasting, etch- ing, and plasma-spraying) were provided by the producer (Modemedical).

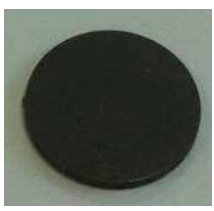

Fig. 1. Sand blasted specimen.

In the experimental measurement phase, three representative differently surface treated flat specimens were used in this research with different measurement parameters to validate the performance of different sampling methods (Fig. 1). Roughness measurements and surface topography characterization were performed by stylus profilometry to obtain $R_{\mathrm{a}}$ values that was measured two-dimensionally in contact mode by the profilometry equipped with point radius $2 \mu \mathrm{m}$ conisphere diamond stylus tip size (point angle $90^{\circ}$ ) and $1 \mathrm{mN}$ force selected (Table I).

TABLE I

The specification of contact stylus type profilometer.

\begin{tabular}{c|c}
\hline \hline Measurement method & Stylus profilometer \\
\hline Spatial resolution & $1-2 \mu \mathrm{m}$ \\
$Z$ resolution & $3-16 \mathrm{~nm}$ \\
Range $Z$ & $3-16 \mathrm{~nm}$
\end{tabular}

The roughness data taken from the stylus profilometer were processed in TalySurf Intra software (Fig. 2). In the measurements of contact stylus instrument, $60 \mathrm{~mm}$ stylus arm length, $2 \mu \mathrm{m}$ radius conisphere diamond stylus tip size and $1 \mathrm{mN}$ force (speed $=1 \mathrm{~mm} / \mathrm{s}$ ) were selected [16]. Three repetitive measurements were taken from each of the flat specimens near to the center regions and average roughness values were calculated. The calculations have been done according to the standards ISO 4287:1998 $\left(R_{\mathrm{a}}, R_{\mathrm{z}}, M_{\mathrm{r}}, S_{\mathrm{m}}\right)$, ASME B46.1:2009 (Pc) and ISO 25178-601 standards [17-19].

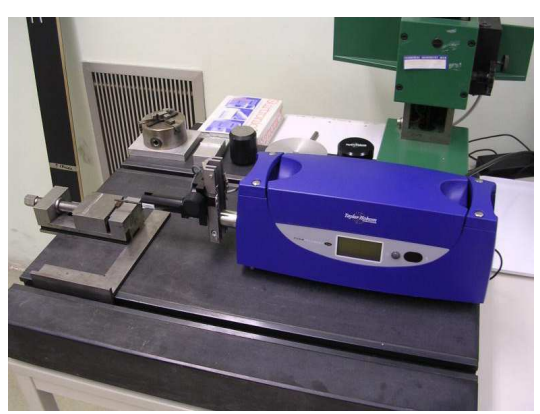

Fig. 2. Stylus profilometer.

From each specimen groups the surfaces of selected samples were investigated by profilometer. Each surface was measured by three longitudinal directed measurement profiles with a combination of different cut-off 
values, traverse lengths. For the analysis of the collected data from surface, Gaussian filter, RC filter was employed for separating roughness from waviness and form to preserve other surface feature with a measurement speed of $1 \mathrm{~mm} / \mathrm{s}$. Traversing length is equal to the sampling length but differs according to the filter type. As mentioned before different cut-off values combined with different filters. These cut-off values should be selected in enough portions for separation waviness from roughness. It is especially important when the roughness wavelength is longer than waviness. The waviness of the surface can be included in the surface roughness profiles with the selection of longer cut-off length used in filtering [8]. There- fore, the values of these cut-off parameters selection can be interpreted as correlation affecting the measurement results.

\section{Results and discussion}

The underlying assumption is that for different surface treated titanium grade 4 samples were measured with the correlation of different cut-off, access length and filter combinations. Three reparative measurements applied for each filter, filter and sample groups and mean values were given in Table II. In total 180 measurements applied with different combinations to conclude the effect of these parameters.

Specimen groups roughness values.

TABLE II

\begin{tabular}{|c|c|c|c|c|c|c|c|c|c|c|c|c|c|c|}
\hline \multicolumn{5}{|c|}{ Sand blasted } & \multicolumn{5}{|c|}{ Sand blasted + hydrofluoric acid etched } & \multicolumn{5}{|c|}{ Sand blasted + nitric acid etched } \\
\hline \multirow{2}{*}{$\begin{array}{l}\text { Cut } \\
\text { off }\end{array}$} & \multirow{2}{*}{ Filter } & \multicolumn{3}{|c|}{ Access } & \multirow{2}{*}{$\begin{array}{c}\text { Cut } \\
\text { off }\end{array}$} & \multirow{2}{*}{ Filter } & \multicolumn{3}{|c|}{ Access } & \multirow{2}{*}{$\begin{array}{l}\text { Cut } \\
\text { off }\end{array}$} & \multirow{2}{*}{ Filter } & \multicolumn{3}{|c|}{ Access } \\
\hline & & 1 & 2 & 3 & & & 1 & 2 & 3 & & & 1 & 2 & 3 \\
\hline \multirow{2}{*}{0.25} & & 278 & 1.407 & 77 & \multirow{2}{*}{0.25} & $\mathrm{n}$ & 1.20 & 1.276 & 62 & \multirow{2}{*}{0.25} & $\mathrm{R}$ & 1.0 & .185 & 1.334 \\
\hline & Gauss & 1.292 & 1.433 & 1.5026 & & Gaus & 1.3912 & 1.4172 & 1.466 & & Gav & 1.2 & 1.261 & 1.3788 \\
\hline \multirow{2}{*}{0.8} & $\mathrm{RC}$ & 1.284 & 1.4508 & 1.5486 & \multirow{2}{*}{0.8} & $\mathrm{RC}$ & 1.211 & 1.4566 & 1.5582 & \multirow{2}{*}{0.8} & $\mathrm{RC}$ & 1.1854 & 1.195 & 1.2174 \\
\hline & Gauss & 1.37 & 1.5012 & 1.5364 & & Gauss & 1.3234 & 1.4108 & 1.4448 & & Gauss & 1.2756 & 1.288 & 1.3558 \\
\hline
\end{tabular}

In order to investigate whether different filter, access and cut-off selections resulted in different values for each surface parameter, the values of these flat dental G4 specimens were grouped according to their surface modifications. $R_{\text {a }}$ parameter, the arithmetical average of surface roughness representing the average deviation of surface profile from the mean line, was selected for the assessment of the results.

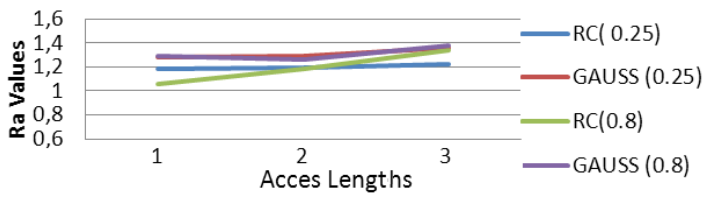

Fig. 3. Sand blasted and nitric acid etched.

As shown in Table II, roughness values and access lengths were dependent according to the specimen groups. It is observed that generally the increase of the traverse lengths caused an increase in roughness values. The evaluation length is equal to the sampling length in the stylus scan direction used to evaluate a portion of traversing length. From the result that is assumed, increasing the sampling length decreased filter performance for separating waviness from roughness. As illustrated by Figs. $3-5$ the roughness value increased with increasing the access length. The cut-off value also was found to be affected by the roughness result. The cut-off was used to determine the wavelengths of waviness and roughness profile. The measurement shows that shorter cut-off filter decreased the waviness effects. All different parameter selection showed similar differences for different surface treated samples.

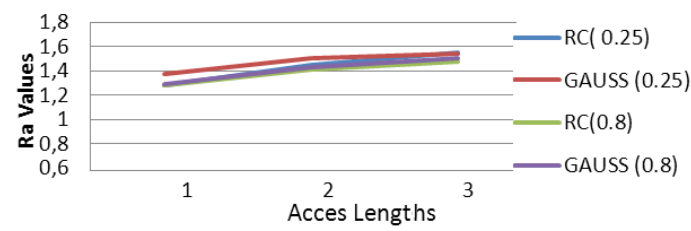

Fig. 4. Sand blasted.

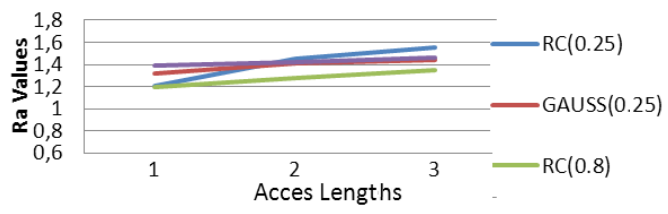

Fig. 5. Sand blasted and hydrofluoric acid etched.

\section{Conclusions}

It can be concluded from the literature review that surface features were one of the most important factors for achievement of dental implant application. Many researchers studied surface characterization of dental implants. Because of the absence of standard procedure for roughness measurement for dental implants, different results have been reported which are confusing the mind about optimal roughness values. In general, results indicate that for different measurement parameters outputs differed from identical roughness values.

In this study it is highlighted that for understanding of biomedical surface sample roughness topography values the measurement, at least the measurement parameters, should be given with the results for the same conditions. 
A well-developed quality procedures for dentistry will assist in defining the most appropriate measurement practice that will become widely needed in future generations and will enable an unambiguous communication of the requirements for the specification of parts and their tolerances that will lead to functional reliability and the assurance of quality during and after certain dental procedures and to assist on optimization its performance in a discipline that to date is largely skill based.

\section{Acknowledgments}

The titanium dental implant samples were provided from Dental ImplantKA — Mode Medical Company.

\section{References}

[1] A. Gupta, M. Dhanraj, G. Sivagami, Intern. J. Dental Sci. 7, 10-10 (2009).

[2] I.M.O. Bernal, I. Risa, K. Hiroki, T. Ken-Ichiro, Y. Naoko, T. Toshi-Ichiro, N. Kuniteru, M. Masahiko, J. Gifu Dental Soc. 35, 89 (2009).

[3] A. Daskalaki, Dental Computing and Applications: Advanced Techniques for Clinical Dentistry, IGI Global, New York 2009 (e-book).

[4] G. Mendonça, D.B.S. Mendonça, F.J.L. Aragão, L.F. Cooper, Biomaterials 29, 3822 (2008).

[5] M.M. Shalabi, A. Gortemaker, M.A. Van't Hof, J.A. Jansen, N.H.J. Creugers, J. Dental Res. 85, 496 (2006).

[6] F.H. Jones, Surf. Sci. Rep. 42, 75 (2001).

[7] M.H. Prado da Silva, G.A. Soares, C.N. Elias, J.H.C. Lima, H. Schechtman, I.R. Gibson, S.M. Best, Mater. Res. 3, 61 (2000).

[8] W.-R. Chang, M. Hirvonen, R. Grönqvist, Safety Sci. 42, 755 (2004).
[9] H.J. Rönold, J.E. Ellingsen, Biomaterials 23, 4211 (2002).

[10] M.N. Durakbasa, W. Pirker, P.H. Osanna, P. Demircioglu, G. Bas, B. Gültekin, in: 14 Joint Int. IMEKO TC1 + TC7 TC13 th + Symp. Intelligent Quality Measurements - Theory, Education and Training, Jena (Germany), Eds.: P. Scharff, G. Linß, Universitätsverlag Ilmenau, Ilmenau 2011, paper No. urn:nbn:de:gbv:ilm1-2011imeko-085:3.

[11] C.N. Eliasa, Y. Oshida, J.H. Lima, C.A. Mullere, J. Mech. Behav. Biomed. Mater. I, 234 (2008).

[12] F.V.G. Brookshire, W. Nagy, V.B. Dhuru, G.J. Ziebert, S. Chada, J. Prosthet. Dent. 78, 86 (1997).

[13] C. Aparicioa, A. Padrós, G. Francisco-Javier, J. Mech. Behav. Biomed. Mater. 4, No. 4, 1672 (2011).

[14] F. Rupp, L. Scheideler, D. Rehbein, D. Axmann, J. Geis-Gerstorfer, Biomaterials 25, 1429 (2004).

[15] W. Barthlott, C. Neinhuis, Planta 202, 1 (1997).

[16] M. Wieland, P. Hänggi, W. Hotz, M. Textor, B.A. Keller, N.D. Spencer, Wear 237, 231 (2000).

[17] ISO 4287:1997 + Cor 1:1998 + Cor 2:2005 + Amd 1:2009; Geometrical Product Specifications (GPS) Surface texture: Profile method - Terms, definitions and surface texture parameters.

[18] ASME B46.1:2009; Surface Texture (Surface Roughness, Waviness, and Lay).

[19] ISO 25178-601:2010; Geometrical product specifications (GPS) - Surface texture: Areal - Part 601: Nominal characteristics of contact (stylus) instruments. 